granular cells on the compressed side was about one third of the contralateral side.

In a group of cases $33 \mathrm{cc} / \mathrm{kg}$ of $30 \%$ urea solution was given intravenously, 24 hours after releasing extradural compression for a period of 48 hours. The animals were sacrificed 1 hour after urea injection. The cellular density was found to be markedly increased both on the compressed and the contralateral sides. The degree of the increase was similar on both sides.

In a group of cases in which $70 \mathrm{cc} / \mathrm{kg}$ of $20 \%$ mannitol solution was given intravenously, the cellular density showed pronounced bilateral increase like in the urea group, but the increase was slightly less on the contralateral side. In a group of cases in which one intravenous injection of $40 \mathrm{mg} / \mathrm{kg}$ of CDP-choline was made, the cellular density increased as markedly as in the urea group on the compressed side, but the density on the contralateral side increased only up to or barely exceeding the normal density. When CDP-choline was given 3 times at intervals of 1 hour the cellular density showed a further increase on the compressed side.

In another group of cases, $10 \mathrm{mg} / \mathrm{kg}$ of water-soluble prednisolone was given intramuscularly once every day since the time of starting extradural compression, and a striking increase in cellular density was observed on the compressed side, whereas its increase on the compressd side, whereas its increase on the contralateral side was roughly in the same degree as in the group urea or mannitol administration.

Thus, as far as the observations on changes in cellular density on the compressed side concern, the ability on counteraction against brain edema was largest in prednisolne and CDP-chline was the next. The ability was somewhat less in urea and mannitol solutions. It seemed that the action of CDP-choline was exerted fairly selectively in the compressed, or highly edematous, region.

\title{
53. Effects of Urea, Mannitol and Low Molecular Dextran on Cerebral Edema
}

\section{-Experimental observation utilizing polygragh-}

Shin Hoshikawa, Hajime Nagal, Sokichi Kayo, Masahiro Furuse

Kazuhiko OKamura, Inazo Toda, Yoshihiko OKa, Ryohei HaKawa

Tatsuya Kobayashi, Atsushi IKeyama, Shigeru Maeda, and Michiaki Hasuo

2nd Department of Surgery, Nagoya University School of Medicine

We observed the effects of urea, mannitol and low molecular dextran on cerebral dema with the various parameters; respiration, systemic blood pressure, cortical $\mathrm{pO}_{2}, \mathrm{pCO}_{2}$, cerebral blood flow (heat clearance method), and EEG 


\begin{tabular}{|c|c|c|c|c|}
\hline \multirow{3}{*}{ Resp. } & cotrol resp. & 2 & & \\
\hline & unchanged & 0 & 10 & 4 \\
\hline & rough, irregular & 9 & 0 & 0 \\
\hline \multirow[t]{3}{*}{$\mathrm{Bp}$} & increased & 0 & 6 & 2 \\
\hline & unchanged & 0 & 4 & 2 \\
\hline & decreased & 11 & 0 & \\
\hline \multirow[t]{3}{*}{$\mathrm{pO}_{2}$} & increased & 0 & 2 & 0 \\
\hline & unchanged & 1 & 4 & 4 \\
\hline & decreased & 10 & 4 & 0 \\
\hline
\end{tabular}

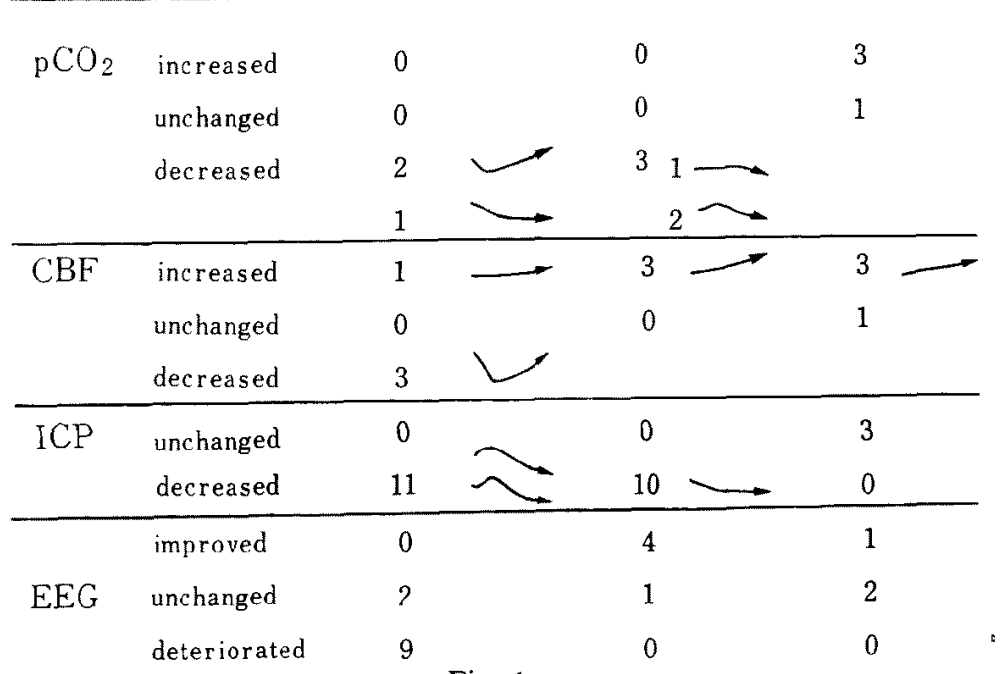

Fig. 1.

were recorded. Cold induced edema was prepared on one side of the hemisphere of 25 dogs weighing 10 to $15 \mathrm{~kg}$. The animals were divided into the following three groups:

Group 1: consisting of 11 dogs, received intravenous infusion of $30 \%$ urea solution of $1.5 \mathrm{gm}$ per $\mathrm{kg}$.

Group 2: 10 dogs received intravenous infusion of $20 \%$ mannitol solution of $3.0 \mathrm{gm}$ per $\mathrm{kg}$.

Group 3: 4 dogs received intravenous infusion of 5\% low molecular dextran of $10 \mathrm{cc}$ pr $\mathrm{kg}$.

Those solutions were administered in 30 minutes.

Group 1: Immediately after the infusion of urea, there was a transient rise of intracranial pressure followed by gradual decrease. In all cases, irregular or rough respiration was observed within 3 to 15 minutes. Systemic blood pressure decreases at the same time, and 2 dogs passed into shock state and died. Cortical 


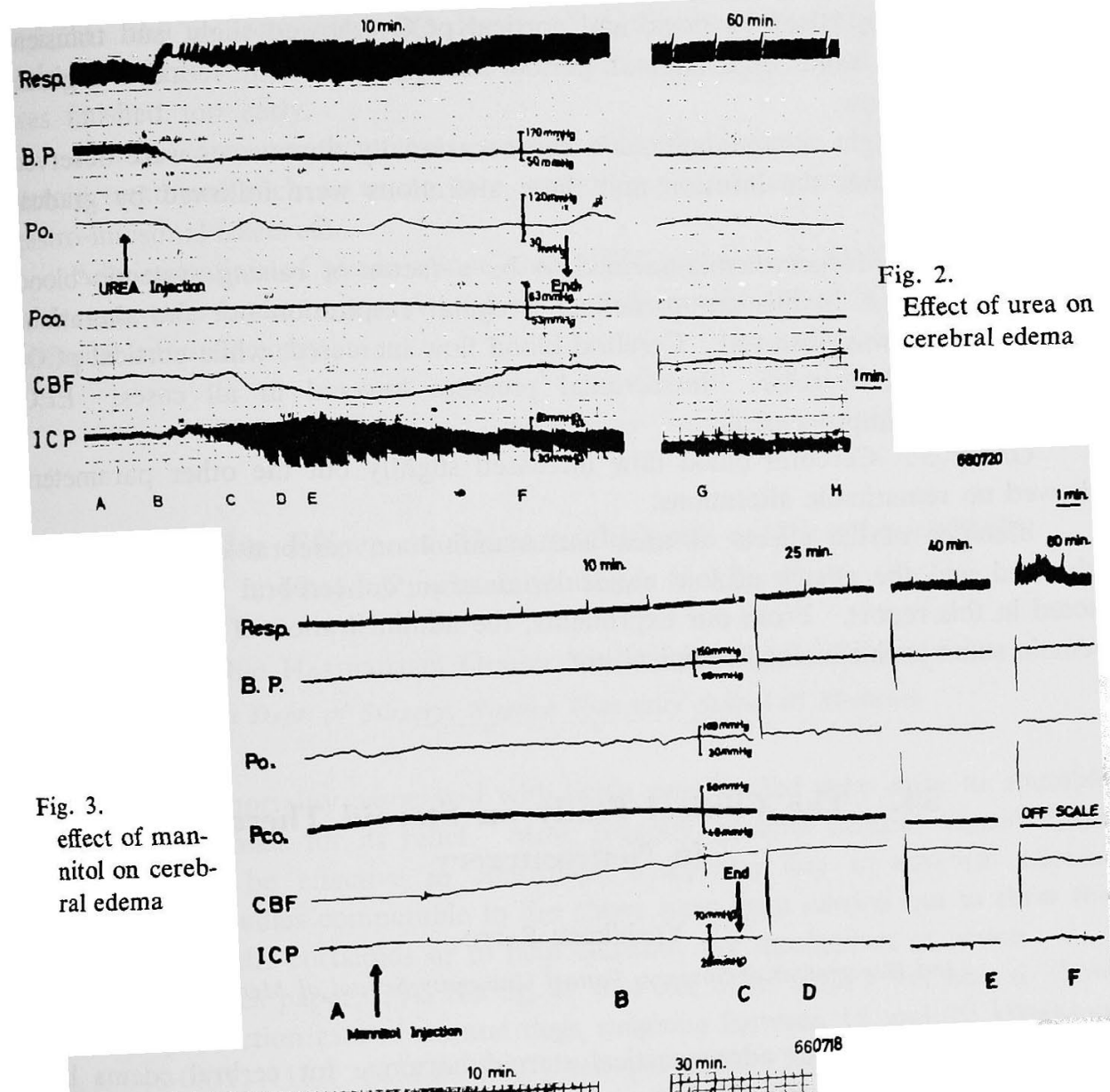

Fig. 3.

effect of man-

nitol on cerebral edema

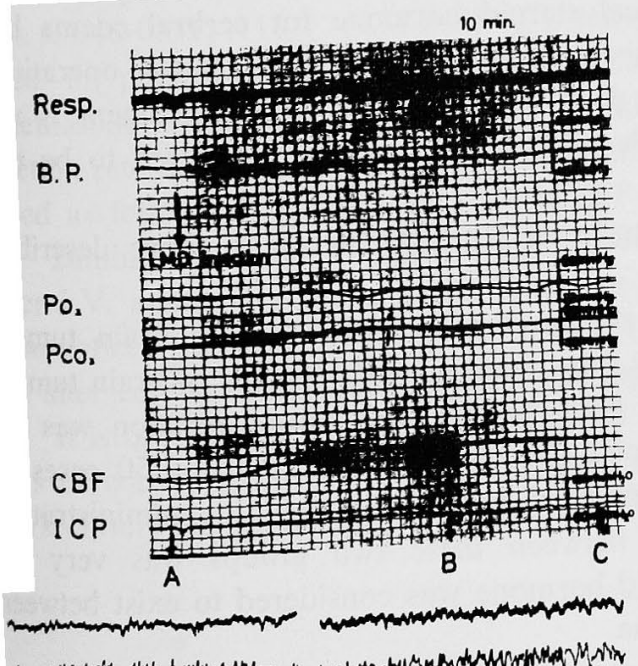

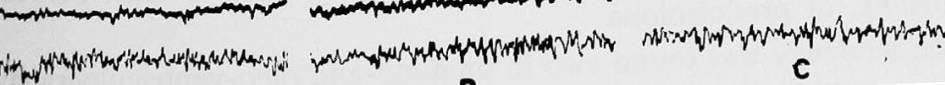
A

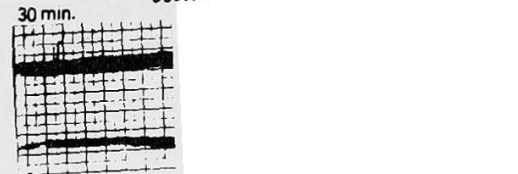

Fig. 4.

effect of L.M.D. on cerebral edema

$\min$

$\int_{150 \mathrm{Cog}}^{100 \mathrm{~N}}$

$c$ 
$\mathrm{pO}_{2}$ decreased in 10 of 11 dogs, and cortical $\mathrm{pCO}_{2}$ showed slight and transient decrease in the same experimental period accompanied with reduced regional cerebral blood flow.

In EEG, slight voltage depression and occasionally slow waves were observed in early stage after the infusion and these alterations were followed by gradual improvements.

Group 2: Hypervolemia seemed to be a factor of raising systemic blood pressure slightly. In this group, neither irregular respiration nor the alterations of cortical $\mathrm{pO}_{2}$ was observed. Cerebral blood flow increased, while cortical $\mathrm{pCO}_{2}$ showed gradual decrease. Intracranial pressure lowered in all cases. EEG revealed slight improvement.

Group 3: Cerebral blood flow increased slightly but the other parameters showed no remarkable alterations.

ifference of the effects of urea and mannitol on cerebral edema was emphasized and the effects of low molecular dextran on cerebral blood flow was noted in this report. From our expriments, the administration of urea seemed to remain some problems for its clinical use.

\title{
54. The Clinical Study on Steroid Therapy in Neurosurgery
}

\author{
Yoshikazu SAITo \\ 2nd Department of Surgery, Totiori University School of Medicine
}

The treatment with adrenocortical steroid hormone for cerbral edema has been commonly done with effect in acute cerebral injury, brain tumor operations and cerebral apoplectic strokes etc. But the dosage of the medicament is not always determined accurately and side effects of them are considered to be not so rare.

Clinical results in the present study on these problems as above described are as follows:

1) Postoperative rise in body temperature in patients with brain tumors was measured compared in two groups. In one group of 15 cases of brain tumors with out steroid therapy, the rise in body temperature after operation was remarkable. But the rise in body temperature in the other group of 50 cases of brain tumors after operation was controlled moderately well by administration of steroid hormone. The differnce between these two groups was very remakable and optimate dosage of steroid hormone was considered to exist between 1.5 and $2.0 \mathrm{mg}$. per $\mathrm{kg}$. of prednisolone.

2) The same tendency was found also in pneumo-and oleo-ventriculography. 